\title{
Variation in seed morphometric traits, germination and early seedling growth performances of Tamarindus indica $\mathbf{L}$.
}

\author{
Belarmain FANDOHAN *, Achille E. ASSOGBADJO, Romain Glèlè KAKAÏ and \\ Brice SINSIN \\ Laboratory of Applied Ecology, Faculty of Agronomic Sciences, University of Abomey-Calavi, 01 BP 526, \\ Cotonou, Benin. \\ *Corresponding author, E-mail: bfandohan@gmail.com, Tel: +22921303084.
}

\begin{abstract}
The purpose of this work was to address provenance variation in Tamarindus indica seed's morphometric traits, germination and early seedling growth. Seed samples were sampled from three populations in Benin and examined for variations in seed morphometric traits, germination response to pretreatment, and seedling growth. Overall, seed traits significantly differed and showed positive correlation with humidity gradient. The effect of the interaction provenances*pre-treatments was significant on the mean germination time $(\mathrm{p}<0.0001)$ but not on the final percentage of germination $(\mathrm{p}=0.937)$. Both direct sowing and cow dung solution soaking ensured $90 \%$ of germination while boiled water soaking seemed to annihilate the capacity of seeds to germinate. Seeds from the Guineo-Congolian region took fewer days to geminate (13.4) than that from the Sudanian region (20.3). Growth speed also varied, with the Guineo-Congolian provenance reaching $46.1 \mathrm{~cm}$ (height) and $0.89 \mathrm{~cm}$ (collar diameter) and the Sudanian provenance, $40.4 \mathrm{~cm}$ and $0.57 \mathrm{~cm}$ respectively, after six month of growth. Results evidence that pre-treatment is not necessarily relevant to reach a high germination percentage for tamarind seeds but may speed germination. The Guineo-Congolian provenance may be preferably used as rootstock onto which further selected cultivars will be grafted and used to rejuvenate traditional agroforestry systems.
\end{abstract}

(C) 2010 International Formulae Group. All rights reserved.

Key words: Seed emergence, seedling growth, early growth speed, Benin.

\section{INTRODUCTION}

The progressively deteriorating situation of the environment under the tropics has often been associated to declining rainfall and over-exploitation of phytogenetic resources by local communities (Gijsbers et al., 1994). To slow down or reverse this trend requires a long-term and diversified production based on tree crops (Leakey, 2001). Among the many woody plants of economic importance commonly used in semi-arid lands, tamarind tree (Tamarindus indica L., Leguminosea-Caesalpinioideae) is a multipurpose tree species daily used by locals for food, medicine and culture (Fandohan et al., 2010). Following the increasing interest on wild fruit trees as key element in strategies building toward poverty alleviation in African countries, $T$. indica has been identified as one of the indigenous fruit trees worthy of domestication in sub-Saharan Africa (Eyog Matig et al., 2002). Its wood is hard and 
durable and its leaves and bark have numerous applications in traditional medicine (Jama et al., 2008). However, its main attraction lies in its fruit production (Diallo et al., 2008).

Domestication of indigenous fruits trees species through agroforestry is seen as one of important issues in transformation of land use in Africa (Sanchez and Leakey, 1997), through the establishment of a better balance between food security and natural resource utilization and is crucial for longterm conservation and use of species under anthropogenic pressure. To be successful, domestication researches have to focus on understanding and overcoming germination problems and building suitable ways and methods for rapid propagation. Propagation by seed is the least expensive means of propagation and is necessary to produce seedlings to be used as rootstocks onto which selected cultivars can be grafted (El-Siddig et al., 2006). Furthermore, to enhance rapid sustainable production of $T$. indica there is needs to understand the basic in situ silvicultural requirements of the species. Thus, a proper understanding of the processes involved in seed germination and initial growth is a prerequisite for tamarind domestication and cultivation (El-Siddig et al., 2006). Germination and propagation studies in tamarind have yielded various findings. Some studies pointed out that tamarind seeds have hard impermeable coat and have proposed several pre-treatment methods to overcome dormancy and stimulate germination. Pretreated with sulphuric acid (El-Siddig et al., 2001; Parameswari et al., 2001; Muhammad and Amusa, 2003), methanol (MacDonald et al., 2002), a mixture of those acids solution (Idu and Omonhinmin, 2001) or hot water (Muhammad and Amusa, 2003) have been reported to significantly increase germination rate of tamarind seeds. However, these methods are risky for locals because of the hurts they may cause if not used with great caution. It is therefore important to develop less dangerous methods to be disseminated in rural areas. Some other studies showed germination success of tamarind seeds by direct sowing without any pre-treatment (ElSiddig et al., 2006) or the effectiveness of the use of simple soaking in fresh water overnight (Prins and Magehembe, 1994), of cow urine or cow dung (Sankaranarayan et al., 1994) to accelerate tamarind seeds germination. This great variation of findings calls concerns about whether (i) there are significant morphological differences among tamarind seeds provenances and (ii) need for pretreatment as well as germination success in the species depend upon the provenance. Thus, this work is to address (i) morphological variation in tamarind seed traits, (ii) the variation of germination success according to provenances, (iii) their response to some key simple pre-treatment methods and (iv) to document their growing performances as for identifying best provenances which may be used as rootstock for "plus cultivars" grafting. In the present study, we tested germination methods using cow urine, hot water soaking and direct sowing as there are exempted of risks and easy to transpose in rural communities. The following questions were addressed: (i) Do seed morphometric traits differ with provenances; (ii) Does the effect of presowing treatments on germination vary with provenances and (iii) Do the growth performances of tamarind seedling vary according to provenances ( $T$. indica $)$ ?

\section{MATERIALS AND METHODS}

\section{Seeds collection}

$T$. indica seeds were collected from three populations representing its distribution range in Benin. In this study, the term provenance denotes the original geographic zone from which seeds were harvested. The Karimama provenance (Krm) represents the Sudanian climatic zone distribution range of the species; the Bassila provenance (Bsl) represents its Sudano-Guinean distribution ranges and the Zinvié provenance (Zinv), its Guineo-Congolian distribution range. Seeds of tamarind were collected from wild trees except for the Zinvié provenance (planted trees). Seeds were separated from pulp, sifted 
to separate damaged ones, air-dried, kept in paper bags and stored at room temperature until the experiment's set up (two months later).

\section{Seed morphometric traits}

To assess the variability in seed morphometric traits, seed length, width, thickness and weight were determined. From each provenance, a total of 30 seeds were randomly selected and used for traits measuring. Measurements were made on individual seed using a digital micro calliper of 0.01 precision (length, width and thickness) and a sensitive balance of 0.001 resolution (weight).

\section{Experimental design}

The experiment design adopted was a complete randomized block comprising three replicates of 15 seeds per combination of treatments' levels and is characterized as follows:

- Three provenances (Krm: Sudanian, Bsl: Sudano-Guinean, Zinv: Guineo-Congolian).

- Three seeds pre-treatments $\left[\mathrm{T}_{0}\right.$ : untreated, $\mathrm{T}_{1}$ : cow dung solution (500 $\mathrm{g}$ in 10 litters) soaking for 24 hours, and $\mathrm{T}_{2}$ : hot water soaking (seeds were soaked for 30 minutes in boiling water after cutting the fire)].

- The experiment was run in real conditions in the Sudanian climatic zone during the wet season. Seeds from each provenance were sown on polythene plastic pots of $20 \mathrm{~cm}$ times $15 \mathrm{~cm}$, initially filled with the local ferruginous subtract. To maintain an ideal moisture condition, watering was done only if not rainy, twice a day: between 7 and 8 AM and between 4 and 5 PM (GMT) following Aho and Kossou (1997).

Germination was scored daily for a period of 45 days. A seed is considered to be germinated when the hypocotyls hook is evident above the soil surface. Number of days to first emergence $\left(\mathrm{E}_{1 \mathrm{st}}\right)$, number of days to $50 \%$ emergence $\left(\mathrm{E}_{50}\right)$, number of days between the emergence of the first and the last seedling, i.e. emergence spread $\left(E_{s}\right)$ and final emergence percentage $\left(E_{f}\right)$ were determined.
The mean germination time (MGT) was computed as follows (Yousheng and Sziklai, 1985):

$$
M G T=\sum n_{i} d_{i} / n
$$

Where: $n=$ total number of seeds germinated during experimental period; $n_{i}=$ number of seed germinated on day $d_{i} ; d_{i}=$ day during germination period.

\section{Seedling growth performances}

Following germination tests, a nursery experiment was performed to examine seedling growth parameters' variability. As the experiment was conducted through the wet season, we benefiting from a temperate intensity of the sunlight allowing seedlings to grow in full sunlight. Watering was only assured on non rainy days. Seedlings' height was measured each 30 days of growth whereas stem collar diameter was measured each 60 days for 180 days (six months).

\section{Data analysis}

Statistical analyses were made using log linear analysis with the Generalized Linear Model procedure of SAS (SAS Inc, 2003) and a Student, Newman and Keuls test. The climatic origins of the provenances were coded according to humidity gradient (1 if Sudanian, 2 if Sudano-Guinean and 3 if Guineo-Congolian). Then, the correlation between morphometric traits of provenances and climatic conditions was made using the spearman rank coefficient.

\section{RESULTS}

\section{Seed morphometric traits}

Significant differences were found among provenances for all seed size characteristics (Table 1). Seeds collected from the Guineo-Congolian region (Zinv) showed the highest values for length, width and weight, followed by seeds from the SudanoGuinean region $(\mathrm{Bsl})$ and then those from the Sudanian region (Krm). Weight of the Guineo-Congolian provenance was nearly two times higher than that of the Sudanian provenance. A positive correlation was detected between seed length width and 
weight and climatic humidity gradient (spearman rank rho $=0.78 ; p<0.01$ ). The wetter the climate, the higher the seed length, width and weight. In contrast, a negative link was observed between seed thickness and humidity gradient (spearman rho $=0.55, p=$ $0.5)$. The dryer the climate, the higher the seed thickness.

\section{Seed germination}

At the end of the experiment, it was noted that irrespective of provenances, all seeds subjected to the treatment $\mathrm{T}_{2}$ (soaking for 30 minutes in boiling water after cutting the fire) did not germinate. Thus, analysis only took into account treatment $\mathrm{T}_{0}$ and $\mathrm{T}_{1}$. As showed in table 2, the Log linear analysis revealed significant effect of provenances and treatments on all the investigated parameters $(p<0.0001)$ except for final emergence. It also showed a significant effect of the interaction provenance*treatment on the parameters. The analysis of the interaction provenance*treatment highlighted a reduction of the number of days to first and $50 \%$ emergence, the emergence spread and the mean germination mean time for the SudanoGuinean provenance (Bsl) (Table 3). In contrast, this effect was slightly significant only for the number of days to first emergence and the mean germination time for the Sudanian provenance (Krm) and for emergence spread for the Guineo-Congolian provenance (Zinv). Overall, the mean germination time was ten days shorter for the Guineo-Congolian provenance compared to the Sudanian provenance which showed the highest value but the final emergence did not significantly vary.

\section{Seedling growth performances}

Significant differences were detected in seedling height after 60, 90, 120, 150 and 180 days of growth (Table 4). Seedling collar diameter showed the same scheme after 120 and 180 days of growth. For both parameters, the provenance from the Guineo-Congolian region showed the highest growth speed (Table 4, Figures 1-2).

Table 1: Means and standard errors of seeds morphometric traits.

\begin{tabular}{lccccc}
\hline Coordinates & Provenances & Length $(\mathbf{c m})$ & Width $(\mathbf{c m})$ & Thickness $(\mathbf{c m})$ & Weight $(\mathbf{g})$ \\
\hline $\mathrm{N} 12^{\circ} 00.031^{\prime}$ & Krm & $1.24 \pm 0.01 \mathrm{c}$ & $0.84 \pm 0.03 \mathrm{c}$ & $0.66 \pm 0.01 \mathrm{a}$ & $0.65 \pm 0.01 \mathrm{c}$ \\
$\mathrm{E} 003^{\circ} 05.279^{\prime}$ & & & & & \\
\hline $\begin{array}{l}\mathrm{N} 08^{\circ} 58.906^{\prime} \\
\mathrm{E} 001^{\circ} 42.017^{\prime}\end{array}$ & $\mathrm{Bsl}$ & $1.40 \pm 0.02 \mathrm{~b}$ & $1.09 \pm 0.04 \mathrm{~b}$ & $0.59 \pm 0.03 \mathrm{~b}$ & $0.7 \pm 0.02 \mathrm{~b}$ \\
\hline${\mathrm{N} 06^{\circ} 38.988^{\prime}}^{\mathrm{E} 002^{\circ} 21.511^{\prime}}$ & Zinv & $1.75 \pm 0.02 \mathrm{a}$ & $1.55 \pm 0.01 \mathrm{a}$ & $0.57 \pm 0.01 \mathrm{~b}$ & $1.21 \pm 0.13 \mathrm{a}$ \\
\hline & & & & \\
\hline
\end{tabular}

Table 2: Results of the analysis of variance for Emergence of first seedling $\left(\mathrm{E}_{1 \mathrm{st}}\right)$, time to $50 \%$ emergence $\left(E_{50}\right)$, emergence spread $\left(E_{s}\right)$, final emergence $\left(E_{f}\right)$ and mean germination time $(M G T)$ of tamarind seeds of three provenances subject to three pre-treatments.

\begin{tabular}{lcccccc}
\hline Sources of variation & \multicolumn{5}{c}{ Significance probabilities $(\boldsymbol{p})$} \\
\cline { 2 - 7 } & $\mathbf{d d l}$ & $\mathbf{E}_{\mathbf{1 s t}}$ & $\mathbf{E}_{\mathbf{5 0}}$ & $\mathbf{E}_{\mathbf{S}}$ & $\mathbf{E}_{\mathbf{f}}$ & $\mathbf{M G T}$ \\
\hline Provenance & 2 & $0.000^{* * *}$ & $0.000^{* * *}$ & $0.000^{* * *}$ & $0.219 \mathrm{~ns}$ & $0.000^{* * *}$ \\
Treatment & 1 & $0.001^{* * *}$ & $0.000^{* * *}$ & $0.000^{* * *}$ & $0.157 \mathrm{~ns}$ & $0.000^{* * *}$ \\
Provenance*treatment & 2 & $0.007 * *$ & $0.000^{* * *}$ & $0.001 * * *$ & $0.937 \mathrm{~ns}$ & $0.000^{* * *}$ \\
Error & 12 & - & - & - & - & - \\
Total & 17 & - & - & - & & - \\
\hline
\end{tabular}

ns: differences are not significant at $\alpha=5 \%$; **differences are significant at $\alpha=1 \%$; ***differences are significant at $\alpha=$ $0.1 \%$. 
Tableau 3: Emergence of first seedling $\left(E_{1 s t}\right)$, time to $50 \%$ emergence $\left(E_{50}\right)$, emergence spread $\left(E_{s}\right)$, final emergence $\left(E_{f}\right)$ and mean germination time (MGT) of tamarind seeds of three provenances subject to three pre-treatments. Data are means of three replicates \pm standard errors.

\begin{tabular}{|c|c|c|c|c|c|}
\hline Provenance & E1st (days) & E50 (days) & Es (days) & Ef (\%) & MGT(days) \\
\hline \multicolumn{6}{|l|}{ Krm } \\
\hline $\mathrm{T}_{0}$ & $13.33 \pm 0.34 \mathrm{ab}$ & $22.00 \pm 0.67 \mathrm{a}$ & $12.67 \pm 0.00 \mathrm{a}$ & $96.67 \pm 3.33 \mathrm{a}$ & $20.61 \pm 0.59 a b$ \\
\hline $\mathrm{T}_{1}$ & $11.33 \pm 0.34 \mathrm{a}$ & $21.67 \pm 0.00 \mathrm{a}$ & $12.00 \pm 0.00 \mathrm{a}$ & $100.00 \pm 0.00 \mathrm{a}$ & $20.01 \pm 0.17 \mathrm{a}$ \\
\hline $\mathrm{T}_{2}$ & - & - & - & - & - \\
\hline \multicolumn{6}{|l|}{ Bsl } \\
\hline $\mathrm{T}_{0}$ & $13.33 \pm 0.34 b$ & $16.67 \pm 0.34 b$ & $10.67 \pm 0.58 b$ & $96.67 \pm 1.93 \mathrm{a}$ & $18.14 \pm 0.02 b$ \\
\hline $\mathrm{T}_{1}$ & $10.33 \pm 0.34 a$ & $12.00 \pm 0.00 \mathrm{a}$ & $8.00 \pm 0.00 \mathrm{a}$ & $100.00 \pm 0.00 \mathrm{a}$ & $12.77 \pm 0.41 \mathrm{a}$ \\
\hline $\mathrm{T}_{2}$ & - & - & - & - & - \\
\hline \multicolumn{6}{|l|}{ Zinv } \\
\hline $\mathrm{T}_{0}$ & $6.67 \pm 0.34 a$ & $12.33 \pm 0.34 a$ & $7.67 \pm 1.00 \mathrm{~b}$ & $93.67 \pm 3.33 \mathrm{a}$ & $13.60 \pm 0.05 a$ \\
\hline $\mathrm{T}_{1}$ & $6.00 \pm 1.00 \mathrm{a}$ & $12.67 \pm 0.34 \mathrm{a}$ & $3.33 \pm 0.34 \mathrm{a}$ & $95.55 \pm 2.23 \mathrm{a}$ & $13.21 \pm 0.31 \mathrm{a}$ \\
\hline $\mathrm{T}_{2}$ & - & - & - & - & - \\
\hline
\end{tabular}

Table 4: Mean and standard error values for stem height and collar diameter $(\mathrm{cm})$ of $T$. indica seedlings.

\begin{tabular}{|c|c|c|c|c|c|c|}
\hline & 30 days & 60 days & 90 days & 120 days & 150 days & 180 days \\
\hline \multicolumn{7}{|c|}{ Height (cm) } \\
\hline Krm & $16.4 \pm 1.54$ & $23.4 \pm 1.8$ & $27.9 \pm 2.7$ & $32.5 \pm 1.84$ & $38.2 \pm 1.9$ & $40.4 \pm 2.5$ \\
\hline Bsl & $17.4 \pm 1.24$ & $25.1 \pm 1.74$ & $30.5 \pm 2.39$ & $35.7 \pm 2.7$ & $40.3 \pm 2.14$ & $41.7 \pm 2.61$ \\
\hline Zinv & $21.5 \pm 0.89$ & $25.6 \pm 1.2$ & $34.1 \pm 2.45$ & $38.5 \pm 1.09$ & $45.2 \pm 2.68$ & $46.06 \pm 2.04$ \\
\hline$p$ & $>0.9$ & $<0.05$ & $<0.01$ & $<0.01$ & $<0.01$ & $<0.01$ \\
\hline \multicolumn{7}{|c|}{ Diameter (cm) } \\
\hline $\mathrm{Krm}$ & - & $0.2 \pm 0.041$ & - & $0.38 \pm 0.07$ & - & $0.57 \pm 0.04$ \\
\hline Bsl & - & $0.2 \pm 0.04$ & - & $0.52 \pm 0.03$ & - & $0.71 \pm 0.01$ \\
\hline Zinv & - & $0.22 \pm 0.02$ & - & $0.61 \pm 0.05$ & - & $0.89 \pm 0.08$ \\
\hline$p$ & - & $>0.5$ & - & $<0.01$ & - & $<0.01$ \\
\hline
\end{tabular}

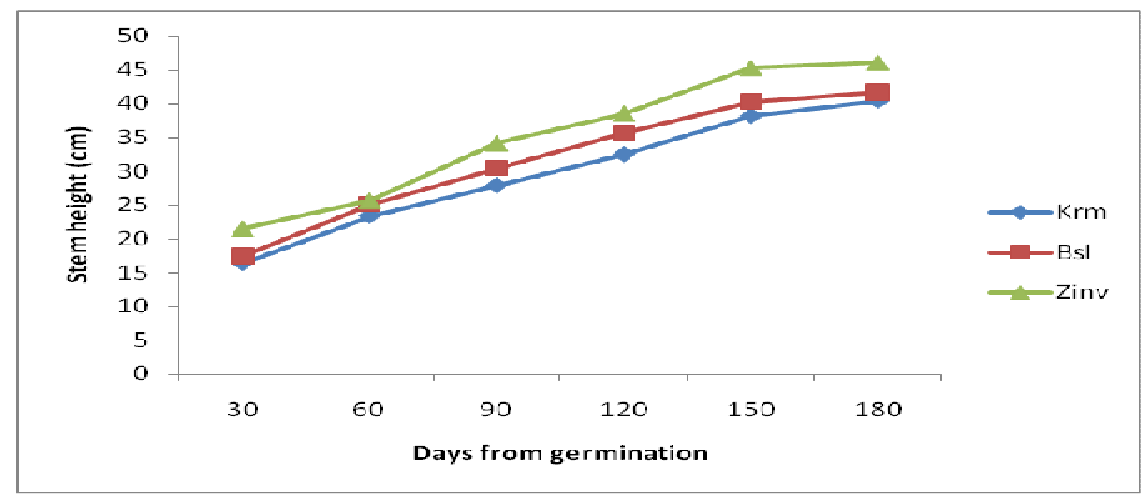

Figure 1: Evolution of mean values for stem height of $T$. indica provenances according to the number of days from germination.

Bsl: Bassila provenance; Krm: Karimama provenance, Zinv: Zinvié provenance. 


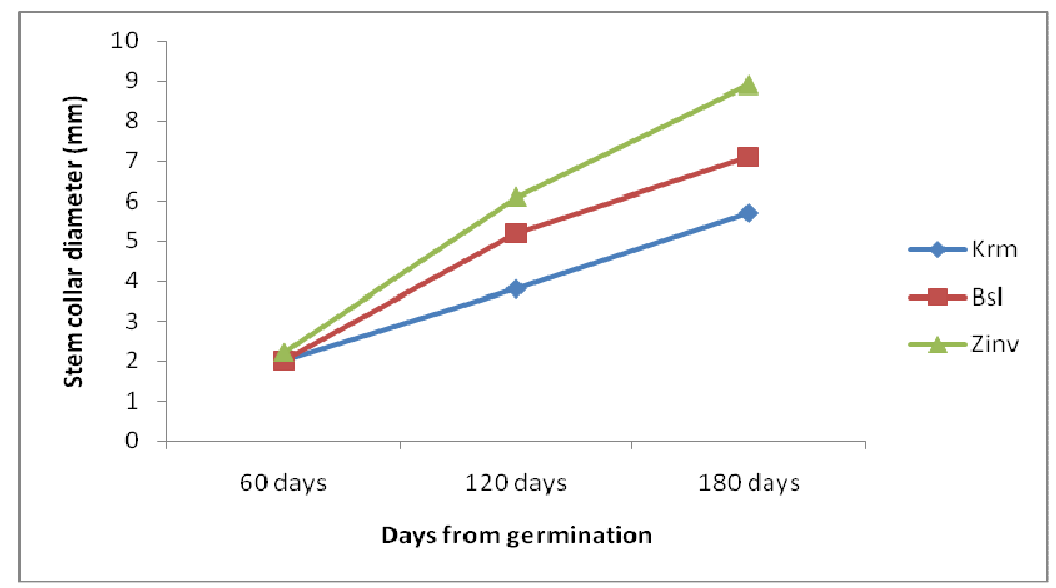

Figure 2: Evolution of mean values for stem collar diameter of $T$. indica provenances according to the number of days from germination.

Bsl: Bassila provenance; Krm: Karimama provenance, Zinv: Zinvié provenance.

\section{DISCUSSION}

This study highlights provenance variation in (i) seed traits, (ii) the effect of pre-treatment on germination and (iii) the growth performances. Tamarind seeds showed significant differences according to their provenances linked to climatic zones. Extensive intraspecific variation in seed traits is common in tropical tree species (Khan et al., 2002; Khan, 2004). Results and observed variations are consistent with a recent studies on tamarind in Burkina Faso (Diallo et al., 2010) and also coroborate previous studies on other species such as Strychnos cocculoides Bak. and Cordia africana Lam. (Mkonda et al., 2003; Loha et al., 2006). These observations confirm that seeds size and germination response partly depend upon geographic provenance. However, the variations may also reflect genetic differences.

The provenance showing larger seeds germinated faster but did not achieve a higher final rate of germination than the others. On the other hand, the positive effect of pretreatment on the investigated germination parameters was clearly apparent for only the provenance from the medium SudanoGuinean climatic conditions (Bsl). Overall, the influence of the interaction provenance* pre-treatment was significant on some germination parameters but did not significantly affect final germination percentage. These disagree with previous findings on tamarind seeds which support the need of chemical scarification to improve germination rate (El-Siddig et al., 2006). Such contrast may reveal a provenance variation in coat hardness and impermeability. In the case of this study, the provenance from the driest region (Krm) might have enough hard impermeable coat to be relatively insensitive to the applied treatment (scarification using cow dung solution) whereas the provenance from the wettest region (Zinv) might portray soft enough coat to need no pre-treatment to quickly germinate. This also suggests that the hardness and the impermeability of the seeds may be positively linked to drought conditions. In addition, the fact that hot water soaking leaded to seed destruction irrespective of provenances whereas previous works reported this pre-treatment to be effective on tamarind seeds, also mirror variability in seed coat hardness and impermeability. However, in case seeds are stored for a relatively long period of time, leading to significant reduction of their moisture content, and hardening of the coat, chemical scarification (e.g. using sulphuric acid) may be needed to overcome dormancy and stimulate germination. But 
since these methods are risky, they should be only used in nursery, assuming that the seedling will be provided to locals by extension offices.

Besides, larger seeds also showed higher growth speed than smaller ones. Many studies have highlighted that seed traits, particularly its mass is determinant for seedling growth and survival during early life stages of plants (Khan, 2004; Meyer and Carlson, 2001). Rapid germination and quick growth might, in that case, be attributed to initial large food reserves in seeds (Khan, 2004; Foster, 1986).

\section{Conclusion}

This study highlights variability in tamarind seed size across climatic conditions and its influence on germinability. Irrespective of the provenances, results from this study provide evidence that pre-treatment is not necessarily relevant to reach a high final germination percentage for tamarind seeds. This is very important especially for resource poor farmers as far as further propagation in traditional agroforestry systems is concerned. Nonetheless, pre-treatment may reduce the mean germination time and thus help mitigating time consumption when producing young plants in nurseries. On the other hand, since the provenance from the GuineoCongolian region showed a significant better performance in term of the mean germination time as well as the growth speed, it may be preferably used as rootstock onto which further selected cultivars will be grafted and used to rejuvenate traditional agroforestry systems.

\section{REFERENCES}

Aho N, Kossou DK. 1997. Précis d'Agriculture Tropicale. Bases et Eléments d'Applications. Editions du Flamboyant: Cotonou.

Diallo BO, Mckey D, Chevallier M-H, Joly HI, Hossaert-Mckey M. 2008. Breeding system and pollination biology of the semi-domesticated fruit tree, Tamarindus indica L. (Leguminosae: Caesalpi- nioideae): Implications for fruit production, selective breeding, and conservation of genetic resources. Afr. J. Biotechnol., 7(22): 4068-4075.

Diallo BO, Joly H, Mc Key D, Hossaert-Mc Key M, Chevallier MH. 2010. Variation des caractères biométriques des graines et des plantules de neuf provenances de Tamarindus indica L. (Caesalpinioideae). Fruits, 65: 153-167.

El-Siddig K, Gunasena HPM, Prasad BA, Pushpakumara DKNG, Ramana KVR, Vijayanand P, Williams JT. 2006. Tamarind, Tamarindus indica $L$. Southampton Centre for Underutilised Crops: Southampton, UK.

El-Siddig K, Ebert G, Ludders P. 2001. A comparison of pre-treatment methods for scarification and germination of Tamarindus indica L. seeds. Seed Sci. Technol., 29(1): 271-274.

Eyog Matig O, Gaoué OG, Dossou B. 2002. Réseaux "Espèces Ligneuses Alimentaire". Compte rendu de la première réunion du Réseau tenue du 1113 décembre 2000 au CNSF Ouagadougou, Burkina Faso 241. Institut International des Ressources Phytogénétiques.

Fandohan AB, Assogbadjo AE, Glèlè Kakaï RL, Sinsin B, Van Damme P. 2010. Impact of habitat type on the conservation status of tamarind (Tamarindus indica L.) populations in the $\mathrm{W}$ National Park of Benin. Fruits, 65: 11-19.

Foster SA. 1986. On the adaptive value of large seeds for tropical moist forest trees: a review and synthesis. Bot. Rev., 52: 261-299.

Gijsbers HJM, Kessler JJ, Knevel MK. 1994. Dynamics and natural regeneration of woody species in farmed parkland in the Sahel region, Province of Passore, Burkina Faso. For. Ecol. Manage., 64: 112.

Idu M, Omonhinmin CA. 2001. Effect of various pretreatments on the seedling growth performance of Tamarindus indica L. Plant Biosyst., 135(2): 165-168. 
Jama BA, Mohamed AM, Mulatya J, Njui AN. 2008. Comparing the "Big Five"': A framework for the sustainable management of indigenous fruit trees in the drylands of East and Central Africa. Ecol. Indic., 8(2): 170-179.

Khan ML. 2004. Effects of seed mass on seedling success in Artocarpus heterophyllus L., a tropical tree species of north-east India. Acta Oecol., 25: 103110.

Khan ML, Bhuyan P, Singh ND, Todaria NP. 2002. Fruit set, seed germination and seedling growth of Mesua ferrea Linn. (Clusiaceae) in relation to light intensity. J. Trop. For. Sci., 14: 35-48.

Leakey RRB. 2001. Win:win landuse stategies for Africa: 2. Capturing economic and environmental benefits with multistrata agroforests. Int. For. Rev., 3: 11-18.

Loha A, Tigabu M, Teketay D, Lundskvist K, Fries A. 2006. Provenance variation in seed morphometric traits, germination, and seedling growth of Cordia Africana Lam. New Forest., 32: 71-86.

MacDonald I, Omonhinmin AC, Ogboghodo IA. 2002. Germination ecology of two savanna tree species, Tamarindus indica and Prosopis africana. Seed Technol., 24(1): 103-107.

Meyer SE, Carlson SL. 2001. Achene mass variation in Ericameria nauseosus (Asteraceae) in relation to dispersal ability and seedling fitness. Funct. Ecol., 15: 274-281.
Mkonda A, Lungu S, Maghembe JA, Mafongoya PL. 2003. Fruit- and seedgermination characteristics of Strychnos cocculoides an indigenous fruit tree from natural populations in Zambia. Agrofor. Syst., 58: 25-31.

Muhammad S, Amusa NA. 2003. Effects of sulphuric acid and hot water treatments on seed germination of tamarind (Tamarindus indica L). Afr. J. Biotechnol., 2(9): 276-279.

Parameswari K, Srimathi P, Malarkodi K. 2001. Standardisation of dormancy breaking treatment in tamarind (Tamarindus indica L.) seeds. Legume Res., 24(1): 60-62.

Prins H, Magehembe JA. 1994. Germination studies on seed of fruit trees indigenous to Malawi. For. Ecol. Manage., 64(2-3): 111-125.

Sanchez PA, Leakey RRB. 1997. Landuse transformation in Africa: three determinants for balancing food security with natural resource utilization. Eur. J. Agron., 7: 15-23.

Sankaranarayan R, Vijayakumar M, Rangasamy P. 1994. Cow urine for ideal tamarind seed germination. Indian Hort., 38(4): 15 .

SAS. 2003. The SAS system for Windows, Version 9.1, SAS Institute Inc., Cary, NC.

Yousheng C, Sziklai O. 1985. Preliminary study on the germination of Toora sinensis (A.JUSS). Roem. Seed from eleven Chinese provenances. For. Ecol. Manage., 10: 269-281. 